\title{
RAPID HPHT ANNEALING OF SYNTHETIC IB-TYPE DIAMONDS
}

\author{
V.N. Kazuchits ${ }^{1}$, N.M. Kazuchits ${ }^{1}$, M.S. Rusetskiy ${ }^{1}$, O.V. Korolik ${ }^{1}$, A.V. Konovalova ${ }^{2}$, \\ O.V. Ignatenko ${ }^{2 *}$ \\ ${ }^{1}$ Belarusian State University, Minsk, 220004 Independence Ave. 4 \\ ${ }^{2}$ State Scientific and Production Association «Scientific and Practical Material Research Center of the \\ NAS of Belarus», 220072, Minsk, P. Brovki str., 19. \\ *Corresponding author E-mail address: Ignatenkoov@yahoo.com (O.V. Ignatenko).
}

Keywords: diamond, RHPHT annealing, Raman scattering, cathodoluminescence, photoluminescence

\begin{abstract}
The paper provides the information on the effects of rapid (1 minute) high pressure high temperature (RHPHT) annealing of synthetic Ib-type diamond plates at temperatures $\left(1900{ }^{\circ} \mathrm{C}\right.$, $2100{ }^{\circ} \mathrm{C}, 2300{ }^{\circ} \mathrm{C}, 2500{ }^{\circ} \mathrm{C}, 2700{ }^{\circ} \mathrm{C}$ ) and pressure of $8 \mathrm{GPa}$. The studies were carried out using the visual analysis, absorption and Raman spectroscopy, photoluminescence and cathodoluminescence. During RHPHT annealing the diamond plates in a high-pressure container were rapidly heated/cooled at a very non-uniform temperature and pressure distribution. All this caused the inhomogeneous plastic deformation of diamond plates. The plastic deformation of diamonds during RHPHT annealing was a powerful "generator" of vacancies. The electron transfer from individual atoms of substituting nitrogen to nitrogen-vacancy centers switched these centers to a negatively charged state. Another accompanying RHPHT annealing process was the diffusion of nitrogen atoms with the formation of it's simple aggregates - H3 defects (at $2300^{\circ} \mathrm{C}$ ). At higher RHPHT annealing temperatures more complex aggregates containing three nitrogen atoms - N3 defects - were generated. RHPHT annealing led to the formation of identical nitrogen - vacancy defects, as did quasi stationary HPHT annealing, but the number of these defects was significantly greater after RHPHT annealing.
\end{abstract}




\section{Introduction}

The heat treatment (annealing) is a common method of controlling diamond properties. Since a diamond at normal pressure is a metastable phase of carbon, it undergoes spontaneous graphitization when heated. Conventionally, the low-temperature annealing in which intrinsic interstitials, vacancies, and hydrogen become movable, can be carried out at normal pressure and without graphitization in the nitrogen or inert gas atmosphere. The generation of color centers in irradiated diamonds [1-3] or the hydrogen diffusion [4] are common examples of such annealing. Modern advances in diamonds annealing technology without pressure allow it to be carried out at high temperatures (low pressure high temperature - LPHT annealing) when impurity nitrogen atoms become mobile [5-9]. The graphitization by LPHT annealing in pure hydrogen atmosphere $[7,10]$ or in vacuum [11] is significantly suppressed. It is impossible to completely get rid of graphitization despite the significant success of LPHT annealing technology.

To minimize the graphitization the high-temperature diamond annealing is preferably carried out under a pressure stabilizing the diamond phase. The high pressure high temperature (HPHT) annealing in diamond synthesis plants is a typical example of such treatment [12]. The pressure and temperature ranges at HPHT annealing is 5-7 $\mathrm{GPa}$ and $1800-2500^{\circ} \mathrm{C}$, respectively. The time for temperature setting in BARS-type devices [13-14] designed for the synthesis of large diamond crystals is about 60 minutes, the annealing duration is from a few minutes to several hours, the cooling time to $600-500^{\circ} \mathrm{C}$ is about 20 minutes. The structural and impurity transformations in synthetic diamonds during HPHT annealing go towards the generation of material similar to natural diamonds. With the account of all advantages of such HPHT annealing, its practical implementation requires expensive equipment and qualified maintenance personnel.

At the same time, HPHT annealing can be performed at a lower cost in high-pressure devices designed for the synthesis of diamond powders [15]. The duration of the heat treatment in the powder synthesis apparatus is comparable to the heating time to a high temperature and is tens of seconds. Using the terminology from silicon-based microelectronics technology we called this treatment rapid high pressure high temperature (RHPHT) annealing. Although the effect of such annealing on diamonds has hardly been studied, it is clear that the samples to be heated will be under very non-equilibrium conditions.

The research results for the defective conversions in RHPHT-treated synthetic Ib-type HPHT diamonds are given below.

\section{Sample preparation and annealing}

The plates made of single crystals of Ib-type diamond synthesized at AdamasInvest LLC, Belarus (Almazot trademark) were subjected to rapid thermal annealing. Diamonds were synthesized by the temperature gradient method in C-Fe-Ni melt at temperatures $1470-1500^{\circ} \mathrm{C}$ and pressure 5.4-5.0 GPa within 70-76 hours [16-17]. The experimental plates were cut along the plane (100) parallel to the base from three crystals grown under the same conditions. A photograph of one of the crystals weighing 1.6 carats is shown in Figure 1. Dashed lines in Figure 1 show the region of the crystal from which the plates were cut. The thickness of the plates was 350-500 $\mu \mathrm{m}$ after the double-sided mechanical polishing. Five rectangular plates with a diagonal size not more than $5 \mathrm{~mm}$ were selected for the experiment. The size limitation of the plates was set by the annealing container diameter. 


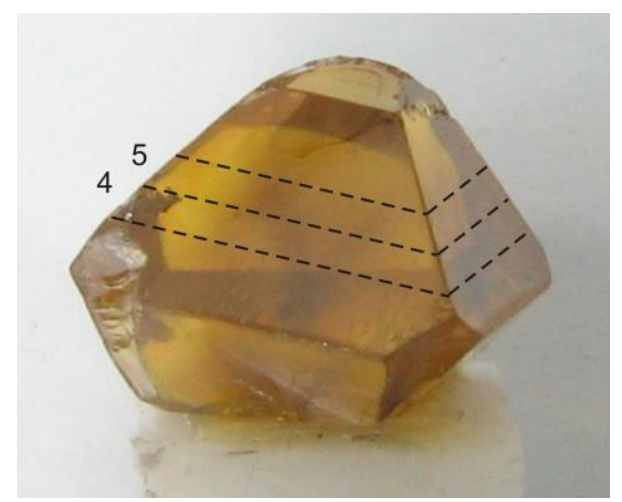

Figure 1 - Photograph of a standard Almazot crystal; experimental plates were cut from the part of the crystal indicated by dashed lines

The diamond plates prepared in this way were annealed at SSPA SPMRC of NAS of Belarus in high-pressure apparatuses with toroid carbide matrices. This type of apparatus is commonly used for the synthesis of diamond and boron nitride micropowders [15]. A high pressure lithographic container with a diamond plate therein was installed in the carbide matrix. Figure 2 shows the arrangement of the diamond plate (1) in the center of the container (2) of the operating volume $222 \mathrm{~mm}^{3}$ and a diameter $5.8 \mathrm{~mm}$. A fine boron nitride powder (3) with a grain size less than $10 \mu \mathrm{m}$ was used to create a quasi-hydrostatic pressure distribution in the working volume of the container. The pressure calibration was carried out at the room temperature by phase transitions of solid solutions of zinc and cadmium sulphides and selenides CdS (2.4 GPa), $\mathrm{Zn}_{0.05} \mathrm{Cd}_{0.95} \mathrm{~S}$ (3.5 GPa), $\mathrm{Zn}_{0.05} \mathrm{Cd}_{0.95} \mathrm{~S}$ (5.3 GPa), CdSe (2.5 GPa), $\mathrm{Zn}_{0.07} \mathrm{Cd}_{0.93} \mathrm{Se}(3.3 \mathrm{GPa})$, $\mathrm{Zn}_{0.13} \mathrm{Cd}_{0.87} \mathrm{Se}(4.1 \mathrm{GPa}), \mathrm{Zn}_{0.2} \mathrm{Cd}_{0.8} \mathrm{Se}(4.6 \mathrm{GPa}), \mathrm{Zn}_{0.3} \mathrm{Cd}_{0.7} \mathrm{Se}(5.6 \mathrm{GPa})$. Temperature calibration was carried out at a pressure of $8 \mathrm{GPa}$ using a platinum-platinum-rhodium (Pt-Pt / $10 \% \mathrm{Rh})$ thermocouple, a graphite-diamond $\left(2600{ }^{\circ} \mathrm{C}\right)$ phase transition, and by the melting points of molybdenum $\left(2700{ }^{\circ} \mathrm{C}\right)$ and iron $\left(1800{ }^{\circ} \mathrm{C}\right)$. The container was heated by electric current passing through cylindrical graphite heater (4) simultaneously with the load application. Diamond plates were annealed at different temperatures $\left(1900^{\circ} \mathrm{C}, 2100^{\circ} \mathrm{C}, 2300^{\circ} \mathrm{C}, 2500^{\circ} \mathrm{C}\right.$, $2700^{\circ} \mathrm{C}$ ) and the same pressure - $8 \mathrm{GPa}$ for a minute.

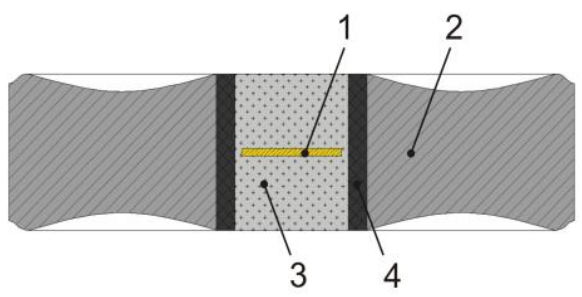

1 - diamond plate;

2 - lithographic stone container casing;

3 - pressure transmitting medium (boron nitride powder);

4 - cylindrical graphite heater.

Figure 2 - Layout of the diamond plate in a high-pressure container at RHPHT annealing

The time of heating to the preset temperature was 60 seconds. On the annealing completion, the pressure was maintained for a cell cooling to the room temperature, which was about 60 seconds. 


\section{Research methods}

A $12^{\mathrm{x}}$ magnification optical microscope was used for the visual analysis and photographing of diamond plates. The plates were photographed on a white background lighted by daylight and ultraviolet (UV) light from a 337-nm laser on a black non-luminescent background. The photographing on a black background lighted by UV light of the plates allowed the visualization of photoluminescence (PL) centers distribution. The birefringence photos were taken in transmitted white light when diamond plates were placed between two crossed polarizers.

The ultraviolet-visible (UV) absorption was measured using a Cary 300 Bio dispersion spectrometer. The measurements were carried out at room temperature in a wavelength range of 200-900 $\mathrm{nm}$ with a pitch of $0.2 \mathrm{~nm}$. The diameter of the diaphragm limiting the measurement area was $0.8 \mathrm{~mm}$.

The absorption of samples in the visible and near infrared (IR) regions of the spectrum cooled to a temperature of $\mathrm{T}=80 \mathrm{~K}$ was measured by a laboratory apparatus with a spectral resolution of $0.4 \mathrm{~nm}$. The light passed through the sample was recorded by a silicon photodetector. The spectral range of measurements was 360-1000 $\mathrm{nm}$. The diameter of the arealimiting diaphragm was $0.8 \mathrm{~mm}$.

The absorption in IR spectrum range was recorded by Vertex 70 Fourier-transform IR spectrometer. The measurements were carried out at room temperature with a resolution of 0.5 $\mathrm{cm}^{-1}$ in the wave number range from 400 to $4000 \mathrm{~cm}^{-1}$ and an average of 60 independent spectrum scans. The diaphragm $1.1 \mathrm{~mm}$ in diameter limiting the measurement area was placed directly on the sample surface. The absorption spectra normalization was carried out related to the intrinsic absorption of the diamond lattice, which was $(4.6 \pm 0.3) \mathrm{cm}^{-1}$ at 2560 and $2430 \mathrm{~cm}^{-1}$ or $(12.8 \pm 0.3) \mathrm{cm}^{-1}$ at 2030 and $1970 \mathrm{~cm}^{-1}$ [18]. The absorption coefficients of the main nitrogen centers were detected by decomposing of the measured spectra into three components associated with the absorption by $\mathrm{C}$-defects (single substituting nitrogen atoms in a neutral charge state), $\mathrm{N}^{+}$-defects (positively charged single substituting nitrogen atoms) and A-defects (nearest adjacent pairs of nitrogen atoms in diamond lattice nodes).

The concentration of C-defects was calculated by the absorption at $1130 \mathrm{~cm}^{-1}$ using the ratio [19]:

$$
\mathrm{N}_{\mathrm{C}}[\mathrm{ppm}]=25 \cdot \alpha_{1130}\left[\mathrm{~cm}^{-1}\right]
$$

where $\alpha_{1130}$ is the absorption coefficient at $1130 \mathrm{~cm}^{-1}$.

The concentration of $\mathrm{N}^{+}$-defects associated with absorption at $1332 \mathrm{~cm}^{-1}$ was calculated by formula from [20]:

$$
\mathrm{N}_{\mathrm{N}}{ }^{+}[\mathrm{ppm}]=5.5 \cdot \alpha_{1332}\left[\mathrm{~cm}^{-1}\right]
$$

where $\alpha_{1332}$ is the absorption coefficient at $1332 \mathrm{~cm}^{-1}$.

The concentration of A-defects was calculated according to the absorption at a wave number of $1280 \mathrm{~cm}^{-1}$ [21]:

$$
\mathrm{N}_{\mathrm{A}}[\mathrm{ppm}]=16.5 \cdot \alpha_{1280}\left[\mathrm{~cm}^{-1}\right]
$$

where $\alpha_{1280}$ is the absorption coefficient at $1280 \mathrm{~cm}^{-1}$.

Raman and PL spectra were measured at the room temperature using a NanoFinder High End spectrometer (LOTIS TII Tokyo Instruments) combined with a three-dimensional scanning confocal microscope. Solid state lasers with a wavelength of $355 \mathrm{~nm}, 473 \mathrm{~nm}, 532 \mathrm{~nm}$, and 785 $\mathrm{nm}$ were used for excitation. The laser radiation was focused on the surface of the samples with a $100^{\mathrm{x}}$ objective to the spot about $1 \mu \mathrm{m}$ in diameter. The power of exciting Raman laser radiation varied from $60 \mu \mathrm{W}$ to $20 \mathrm{~mW}$. Raman spectra were recorded according to the backscattering 
pattern of a silicon CCD matrix cooled to $-59^{\circ} \mathrm{C}$. The spectral resolution was about $0.25 \mathrm{~cm}^{-1}$ when the main Raman line was recorded with a high resolution. The general Raman/PL spectra were recorded with a resolution of no less than $3 \mathrm{~cm}^{-1}$. The signal accumulation time ranged from 1 to $120 \mathrm{~s}$.

The measurements of cathodoluminescence (CL) spectra of liquid nitrogen cooled samples were carried out using a laboratory device with a spectral resolution of $0.2 \mathrm{~nm}$ and a photomultiplier as a photodetector [22]. The spectral range of measurements was 360-900 nm. The luminescence was excited by an electron beam focused on the sample surface to a spot about $1 \mathrm{~mm}$ in diameter. All measurements were performed under the same excitation and recording conditions.

\section{Results and discussion}

\section{Visual analysis}

Table 1 shows photographs of Almazot plates before and after annealing. Annealed plates were etched for 5 minutes in a potassium dichromate boiling solution in sulfuric acid before photographing to remove the surface graphitized layer. As shown in photographs given in Table 1 the original Almazot plates are non-uniformly colored in yellow. The cubic growth sectors that are clearly seen in the central part of plates No. 4102-5, No. 4102-4, and No. 2669-5 are almost colorless or colored in light yellow. The octahedral growth sectors at the plate periphery are colored in yellow. The yellow intensity of synthetic HPHT Ib-type diamonds is determined generally by the $\mathrm{C}$-defect absorption value [1,23-25]. The darker yellow corresponds to a higher concentration of $\mathrm{C}$-defects. The standard concentration of $\mathrm{C}$ defects in yellow Almazot diamonds is $100-200$ ppm [17].

Table 1 Photos of Almazot plates before and after RHPHT annealing

\begin{tabular}{|l|l|l|l|l|}
\hline \multirow{2}{*}{\begin{tabular}{c} 
Plate No., $\begin{array}{c}\text { annealing } \\
\text { temperature }\end{array}$ \\
\cline { 2 - 5 }
\end{tabular}} & daylight & UV lighting & daylight & birefringence \\
\hline $\begin{array}{l}4102-5, \\
\mathbf{1 9 0 0}^{\circ} \mathbf{C}\end{array}$ & & & & \\
\hline
\end{tabular}




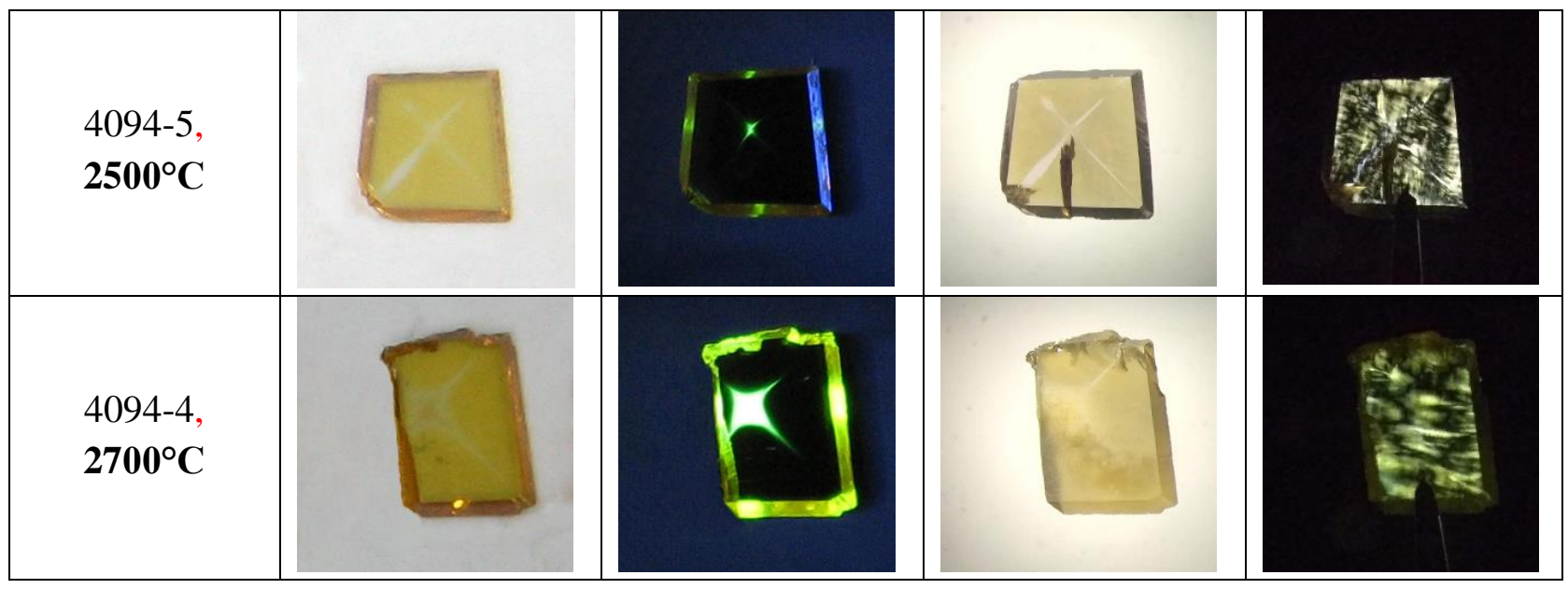

The green PL related to Ni-containing defects [10, 25-30] was observed in the central part of the plates under ultraviolet illumination. The green PL is localized in octahedral growth sectors bordering the cubic sector in the central part of plates No. 4102-5, No. 4102-4, and No. 2669-5. The cubic growth sector was either absent or had a small size in plates No. 4094-5 and No. 4094-4. The green PL in these plates is mainly localized near the edges of the octahedral growth sectors. PL had the maximum intensity at the edge between growth sectors in all plates. PL intensity abruptly disappeared in the cubic growth sectors, while it gradually declined in the octahedral sectors. Such distribution of PL intensity reflected effective nickel capture by intersector edges and octahedral growth sectors and the low efficiency of nickel capture by cubic sectors during synthesis [10, 28-29].

The color of the cubic growth sectors practically did not change, and the octahedral sectors became light yellow after RHPHT annealing. The edge between the cubic and octahedral sectors was marked more clearly. The surface of plates annealed at temperatures above $2300^{\circ} \mathrm{C}$ became matte greatly diffusing the visible light. The cracks occurred in plates No. 2669-5 and No. $4094-5$ annealed at $2300^{\circ} \mathrm{C}$ and $2500^{\circ} \mathrm{C}$, respectively, and plate No. $4102-4$ collapsed. The cracks were formed in plane (110) and did not spread further than the middle of the plates. Thus, the relative shift of different parts of the plates during RHPHT annealing was insignificant. The destruction of plate No. 4102-4 was mainly caused by its large size and possible contact with the walls of the high pressure container during RHPHT annealing. Note the significant surface graphitization of plate No. $4094-4$ after annealing at $2700^{\circ} \mathrm{C}$. It seems that the pressure generated by the plant during RHPHT annealing at $2700^{\circ} \mathrm{C}$ was insufficient to stabilize the diamond phase.

The green PL region a little spread to the octahedral growth sectors (the corresponding photographs are not shown in Table 1) after RHPHT annealing and occupied a large area. The spread of green PL was related to the generation of additional nickel-containing centers during annealing [10]. The green PL was absent in cubic growth sectors, as before RHPHT annealing.

The cross-polarization microscopy was used to reveal stresses. The dark field condition was achieved by two cross-polarizers. The deviation from the dark field condition arising due to the birefringence gave the optical contrast. Due to the varying of birefringence with stress, we could identify its distribution. The photographs in Table 1 in "crossed polarizers" made it possible to visualize the stress distribution in diamond plates after RHPHT annealing. The birefringence was not observed before RHPHT annealing and at annealing temperatures not higher than $1900^{\circ} \mathrm{C}$ (see photo of plate No. 4102-5). As can be seen from the photo of plate No. $4102-4$, the stressed areas appeared after RHPHT annealing at $2100^{\circ} \mathrm{C}$ as large bright spots near 
the edge of the cubic and octahedral growth sectors. The intensity of the transmitted light indicated that the stress amount in this plate decreased towards the periphery of the octahedral sectors. The pattern of stress distribution at higher temperatures was formed by alternating light and dark stripes directed from the center of the plate to its periphery (see photo No. 2669-5 and No. 4094-5). The increase of RHPHT annealing temperature to $2300^{\circ} \mathrm{C}$ and $2500^{\circ} \mathrm{C}$ was accompanied by the reduction of the stress strips size with the simultaneous increase of their quantity per area unit. The size of the stressed strips increased and their density decreased after the maximum temperature of RHPHT annealing (see photo No. 4094-4).

The birefringence in diamonds was observed after the plastic deformation caused by the graphitization during the elastic deformation near inclusions, dislocations, grain edges, and edges of growth sectors [31-34]. The possible cause of stress generation in our case was the plastic deformation of the plates during RHPHT annealing. It is obvious that the pressure was not hydrostatic, but was heterogeneously distributed during RHPHT annealing. This is evidenced by the cracks in the plates appeared after the annealing at temperatures of $2300^{\circ} \mathrm{C}$ and $2500^{\circ} \mathrm{C}$. The inhomogeneous pressure distribution during RHPHT annealing caused the plastic deformation and stress in the plates manifested in the birefringence pattern and in the spectral shift of the CRC main line.

\section{Raman scattering}

Figure 3a (using the example of plate No. 2669-5) shows standard Raman spectra of Almazot from cubic and octahedral growth sectors before RHPHT annealing. The spectra were measured at room temperature. The spectra contained a very intense narrow line (R) at $1332 \mathrm{~cm}^{-1}$ of the single-phonon light scattering in diamond and pronounced double-phonon scattering band (R2) in the range of 2200 to $2660 \mathrm{~cm}^{-1}$ before RHPHT annealing. There were no signs of graphite phase in the Raman spectra [35]. The spectrum from the octahedral sector contained a line at $800 \mathrm{~cm}^{-1}(491 \mathrm{~nm})$ that is most likely related to luminescence. The spectral position of the Raman main line was at $1332.15 \mathrm{~cm}^{-1}$ before RHPHT annealing. Its full width at half maximum (FWHM) was $1.63 \mathrm{~cm}^{-1}$ in the cubic growth sector with about $10 \mathrm{ppm}$ of the nitrogen concentration and $1.75 \mathrm{~cm}^{-1}$ in the octahedral sectors with about $180 \mathrm{ppm}$ of the nitrogen concentration. The Raman main line width in structurally perfect nitrogen-free IIa-type diamonds was about $1.6 \mathrm{~cm}^{-1}$ [36-39]. Therefore, the pre-annealing expansion of line $1332 \mathrm{~cm}^{-1}$ with respect to IIa-type diamonds for plate No. 2669-5 was related to the higher nitrogen concentration, as [37, 39].
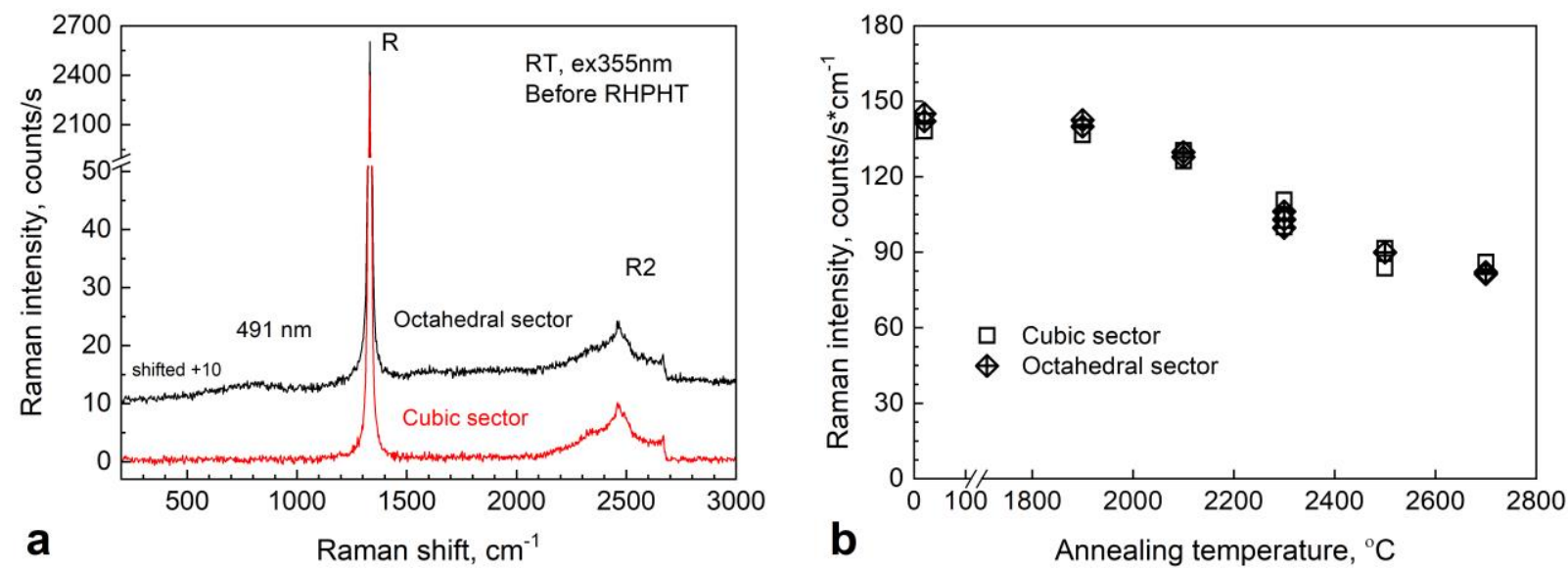

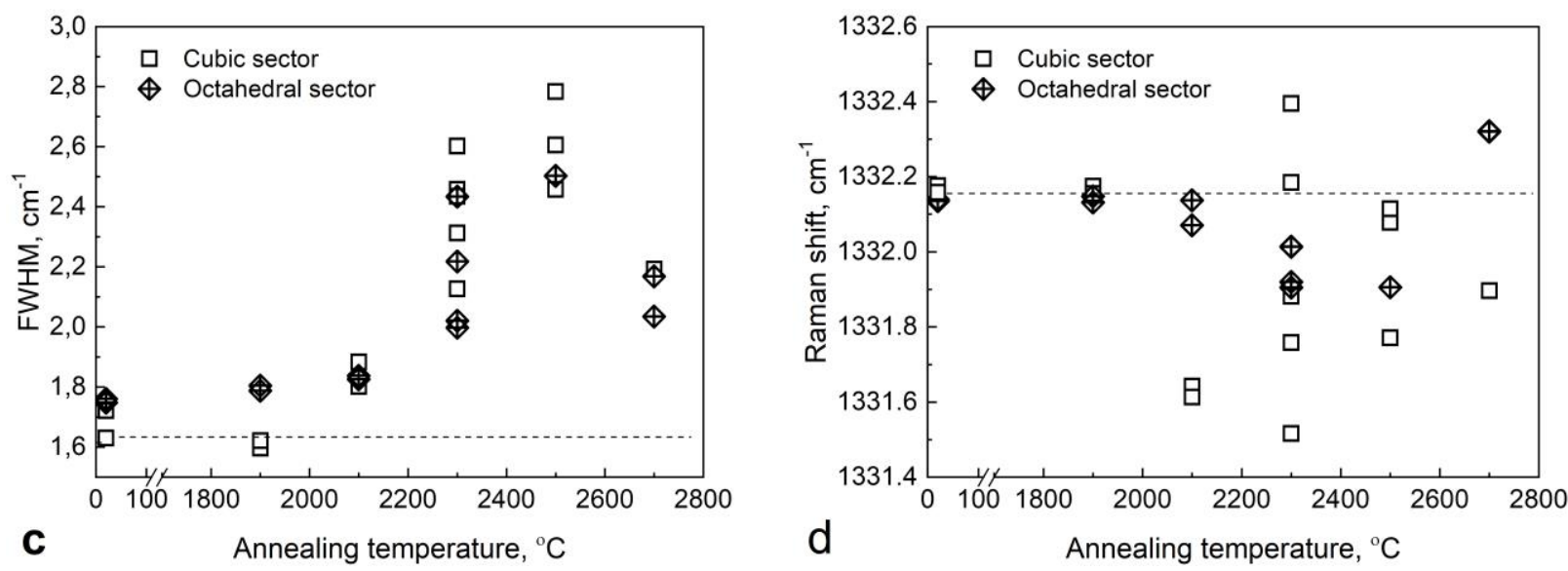

Figure 3 - Raman spectra of Almazot (a) from the cubic and octahedral sectors before RHPHT annealing, (b) integral intensity; (c) FWHM, and (d) the spectral position of $1332 \mathrm{~cm}^{-1}$ line vs. temperature RHPHT annealing. The dashed line shows the parameters of $1332 \mathrm{~cm}^{-1}$ line in nitrogen-free areas of the plates before RHPHT annealing

The Raman intensity decreased and intense PL appeared after RHPHT annealing. The laser excitation with a wavelength of $785 \mathrm{~nm}$ was used to suppress PL.

Figures 3b, 3c, 3d show the changes in the Raman main line parameters after RHPHT annealing. Raman spectra were recorded at the excitation of randomly selected areas on the surface of plates in cubic and octahedral growth sectors. As you can see, $1332 \mathrm{~cm}^{-1}$ line widened and in most cases shifted to smaller wave numbers, its integral intensity decreased monotonically with the increase in RHPHT annealing temperature. The significant variation in the spectral position and $1332 \mathrm{~cm}^{-1}$ line width within the plate was observed in both cubic and octahedral growth sectors.

The shift and broadening of the main Raman scattering line was caused by the plastic deformation of diamond during RHPHT annealing and the stresses related to the deformation. As can be seen from the birefringence photographs in Table 1, the diamond plates were locally stressed after RHPHT annealing. The density of the stressed regions in the plates increased with increase of RHPHT annealing temperature. The shift in the spectral position of the main Raman scattering line of diamonds is linearly related to elastic stresses [40-43]. The shift to lower values of the wave number corresponded to the expansion of the diamond crystal lattice, while the shift to the higher wave numbers corresponded to its compression. We estimated the value of elastic stresses $\sigma$ in direction <001> using the expression given in [43]:

$$
\sigma=0.49 \cdot\left[\mathrm{GPa} / \mathrm{cm}^{-1}\right] \cdot \Delta v\left[\mathrm{~cm}^{-1}\right]
$$

where $\Delta v$ is the difference between the spectral position of $1332 \mathrm{~cm}^{-1}$ line before and after RHPHT annealing. Taking into account the above expression, the elastic stress value between the most compressed and stretched regions of the plate was about $0.43 \mathrm{GPa}$ after RHPHT annealing at a temperature of $2.300^{\circ} \mathrm{C}$.

\section{Absorption}

\section{Visible-near IR range}

The absorption spectra of Almazot octahedral growth sectors in the visible spectral range are shown in Figure 4. Almazot plates absorbed intensively the radiation with wavelengths less 
than $500 \mathrm{~nm}$. Such absorption shown as an example in Fig. 4a is typical for synthetic HPHT diamonds containing $\mathrm{C}$-defects and determined their yellow color [1, 13, 23-24]. The absorption maximum of C-defects was at $270 \mathrm{~nm}[2,23]$. The samples were almost non-transparent at the absorption maximum, and the spectra contained only the long wavelength absorption edge of Cdefects starting from $500 \mathrm{~nm}$ [13] at C-defects concentration more than $50 \mathrm{ppm}$.
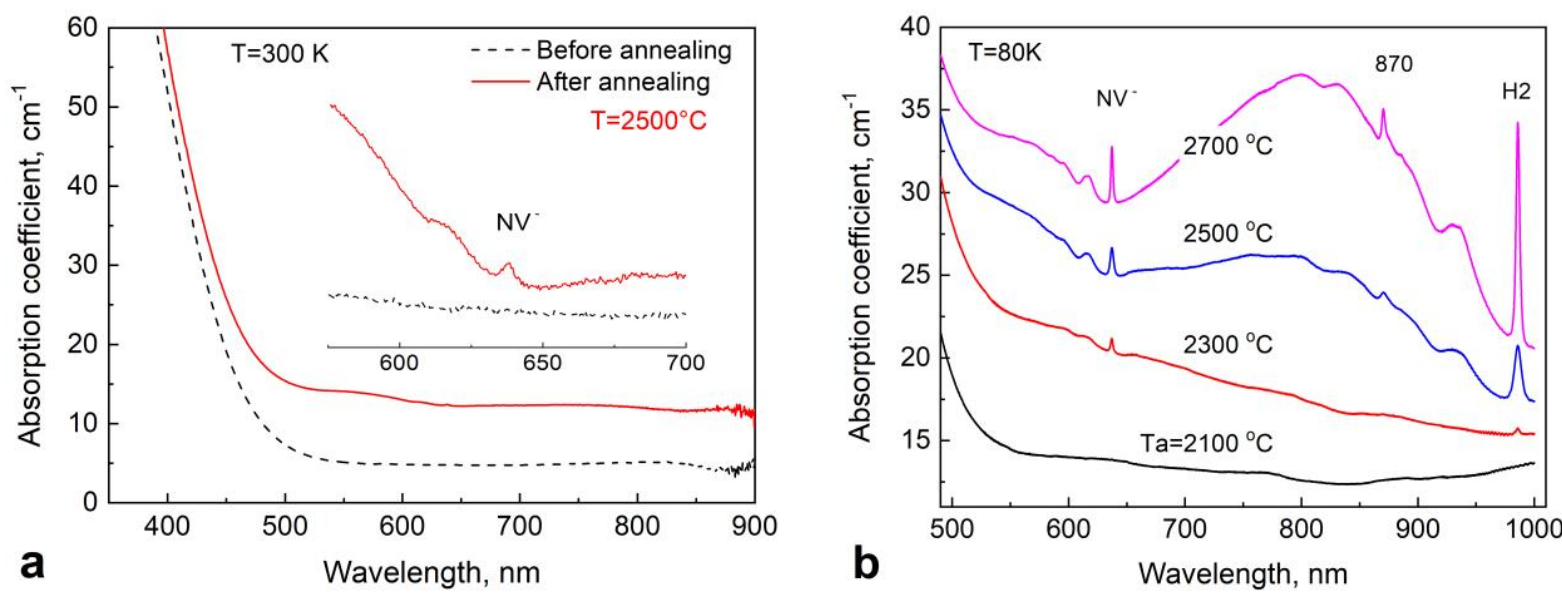

Figure 4 - Absorption spectra of octahedral growth sectors in Almazot plates: a) - at room temperature before and after RHPHT annealing at $\mathrm{T}=2500^{\circ} \mathrm{C}, \mathrm{b}$ ) - at liquid nitrogen temperature after RHPHT annealing. The inset in Fig. 4a shows a part of the spectrum in the vicinity of the $\mathrm{NV}^{-}$-center

The surface of the diamond plates became matte and the absorption spectra shifted along the ordinate axis to larger values by approximately $4-7 \mathrm{~cm}^{-1}$ due to light scattering after RHPHT annealing (see Fig. 4a). The line at $638 \mathrm{~nm}$ appeared at the spectra of absorption by octahedral growth sectors starting from $2100^{\circ} \mathrm{C}$ temperature (see the inset in Fig. $4 \mathrm{a}$ ). The absorption at 638 $\mathrm{nm}$ in cubic growth sectors and in the central luminescent areas of the plates was practically absent. Such distribution of $638 \mathrm{~nm}$ centers is typical for synthetic HPHT Ib-type diamonds [44] in which they were formed mainly in (111) growth sectors and were almost absent in (100) sectors.

$638 \mathrm{~nm}$ center $\left(\mathrm{NV}^{-}\right.$-center) was related to the nitrogen-vacancy complex in the negative charge state [45]. This center is typical for all nitrogen-containing diamonds, especially intense in Ib-type diamonds where the C-form of nitrogen prevails. $\mathrm{NV}^{-}$-center in Ib-type diamonds is formed after any type of irradiation and subsequent annealing at vacancy migration temperatures (46-47). The formation of $\mathrm{NV}^{-}$-centers was also observed after the plastic deformation of diamonds and high-temperature annealing under pressure [48]. The ratio [20] between concentrations $\left(\mathrm{cm}^{-3}\right)$ of $638 \mathrm{~nm}$ centers and the integrated absorption of their respective zerophonon lines (in $\mathrm{meV} \mathrm{cm}^{-1}$ ) for measurements at $80 \mathrm{~K}$ is determined as follows:

$$
\mathrm{N}_{\mathrm{NV}}{ }^{-}\left[\mathrm{cm}^{-3}\right]=8.9 \cdot 10^{15} \cdot \mathrm{I}_{638}\left[\mathrm{meV} \cdot \mathrm{cm}^{-1}\right]
$$

where $\mathrm{I}_{638}$ is the area under $\mathrm{NV}^{-}$-center line in the absorption spectra presented in units of $\left[\mathrm{meV} \cdot \mathrm{cm}^{-1}\right]$.

The transformation of the absorption spectra with increase of RHPHT annealing temperature of diamond plates is shown in Figure $4 \mathrm{~b}$. To obtain more distinct structure of the spectra and to extract the concentration of $\mathrm{NV}^{-}$-centers the diamond plates were cooled to the temperature of liquid nitrogen during absorption measurements. As can be seen from Figure $4 \mathrm{~b}$ 
additional absorption lines appeared at $870 \mathrm{~nm}$ and $986 \mathrm{~nm}$ in the spectra along with the line of $638 \mathrm{~nm}$ after RHPHT annealing at $2300^{\circ} \mathrm{C}$. The width, integrated intensity of $638 \mathrm{~nm}, 870 \mathrm{~nm}$, $986 \mathrm{~nm}$ lines, and the concentration of $\mathrm{NV}^{-}$-centers calculated using expression (5) are shown in Table 2. The intensity of all lines increased due to RHPHT annealing temperature.

Table 2 - Some characteristics of absorption by defective centers after RHPHT annealing

\begin{tabular}{|c|c|c|c|}
\hline \multirow{2}{*}{$\begin{array}{c}\text { RHPHT annealing } \\
\text { temperature, }{ }^{\circ} \mathrm{C}\end{array}$} & \multicolumn{3}{|c|}{ FWHM, meV / integrated intensity, $\mathrm{meV} \cdot \mathrm{cm}^{-1} /$ concentration, $\mathrm{cm}^{-3}$} \\
\cline { 2 - 4 } & $638 \mathrm{~nm}\left(\mathrm{NV}^{-}\right)$ & $870 \mathrm{~nm}$ & $986 \mathrm{~nm}(\mathrm{H} 2)$ \\
\hline 1900 & - & - & - \\
\hline 2100 & $5.80 / 0.20 / \mathbf{1 . 7 6 e 1 5}$ & - & - \\
\hline 2300 & $7.67 / 6.21 / \mathbf{5 . 4 7 e 1 6}$ & $6.87 / 0.39$ & $4.90 / 1.67$ \\
\hline 2500 & $10.39 / 17.39 / \mathbf{1 . 5 3 e 1 7}$ & $8.68 / 4.39$ & $8.92 / 29.44$ \\
\hline 2700 & $6.90 / 23.90 / \mathbf{2 . 1 0 e 1 7}$ & $4.76 / 8.38$ & $4.88 / 65.14$ \\
\hline
\end{tabular}

The $986 \mathrm{~nm}$ center ( $\mathrm{H} 2$ center) is an A-defect that has captured the vacancy in the negative charge state forming a structure of (NVN) ${ }^{-}$type - a pair of substituting nitrogen atoms separated by a negatively charged vacancy $[45,49,50]$. A negative vacancy charge is obtained by capturing a weakly bound electron from closely spaced nitrogen atoms in the C-form [2, 49, 51]. The line at $870 \mathrm{~nm}$ is generated due to the interaction of $\mathrm{H} 2$-center with its own local vibrations with the energy of about $167 \mathrm{meV}$ according to [50]. The formation of H2-centers is the firm evidence of the nitrogen aggregation during RHPHT annealing. The increase in the absorption intensity at $986 \mathrm{~nm}$ simultaneously with the increase in RHPHT annealing temperature indicates the increase in the aggregated nitrogen concentration.

It should be noted that absorption spectroscopy methods did not reveal nitrogen-vacancy centers in the neutral charge state after RHPHT annealing, such as $\mathrm{H} 3$ at $503 \mathrm{~nm}(\mathrm{NVN})^{0}$ and at $575 \mathrm{~nm}\left(\mathrm{NV}^{0}\right)$. This is possible if the concentration of C-defects significantly exceeds the concentration of all nitrogen-vacancy centers corresponding to our case. In fact, the usual concentration of C-defects in Almazot yellow crystals was about 100-200 ppm [7, 16, 17] and the concentration of NV-centers, for example, was about 1 ppm (see Table 2).

\section{IR range}

Figure 5 shows the absorption spectra in the IR spectral range before and after RHPHT annealing, for example, at a temperature of $2700^{\circ} \mathrm{C}$. The measurements were carried out in the central part of the plate (Figure 5a) and on the periphery of the plate in the octahedral growth sector (Figure $5 b$ ). The similar measurements were performed for all plates. 

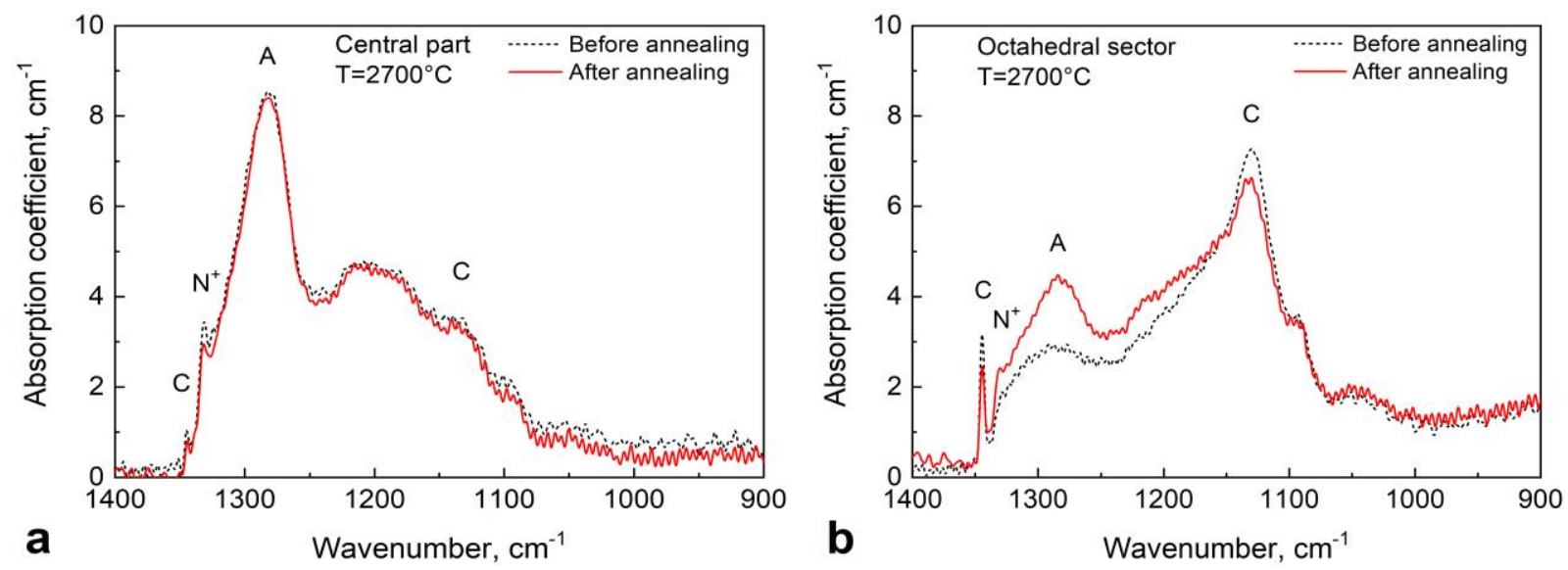

Figure 5 - Absorption spectra in the IR spectral range before and after RHPHT annealing: a) in the central part of the plate, b) - the octahedral growth sector at the periphery of the plate

The structure of the IR absorption spectra in the central part of the plates before RHPHT annealing was almost the same for all samples. The absorption by the simplest aggregates - the A-form of nitrogen at $1280 \mathrm{~cm}^{-1}$, related to the oscillations of two nearest nitrogen atoms at the diamond lattice nodes, prevailed. The nitrogen concentration in the A-form for the spectrum of sample 4094-4 shown in Figure 5a was about $125 \mathrm{ppm}$. The absorption of single isolated nitrogen atoms at the lattice nodes (C-form of nitrogen) at 1130 and $1345 \mathrm{~cm}^{-1}$ corresponded to a concentration of about $38 \mathrm{ppm}$. The absorption related to the ionized C-form of nitrogen, $\mathrm{N}^{+,}$was about $10 \mathrm{ppm}$. As shown in Figure 5a, the absorption spectrum for the central part of the plate practically did not change after RHPHT annealing at $2700^{\circ} \mathrm{C}$. The absence of changes was due to the fact that a significant part of nitrogen in the central area of the plates has been already aggregated during the synthesis [7, 10, 29, 52]. The additional short-term RHPHT annealing did not lead to the noticeable additional nitrogen aggregation in these areas even at $2700^{\circ} \mathrm{C}$. Only a slight increase in absorption by $\mathrm{N}^{+}$form of nitrogen can be noted. This increase can be either due to the formation of additional nitrogen-nickel centers or mismatch of the IR probing areas before and after annealing.

In contrast, the spectra from octahedral growth sectors at the plate periphery changed after RHPHT annealing due to the aggregation of nitrogen from C- to A-form [7, 10, 53-55]. The nitrogen concentration calculated from the absorption spectra for the peripheral areas of the plates is shown in Table 3. As shown in Figure 5b, the nitrogen in the octahedral sectors of the plates was mainly in C-form at the concentration of about 169 ppm before RHPHT annealing. The absorption of C-form decreased to $139 \mathrm{ppm}$ after RHPHT annealing at $2700^{\circ} \mathrm{C}$. In contrast, the absorption of A-form nitrogen increased from 8 to $36 \mathrm{ppm}$ after RHPHT annealing. The concentration of $\mathrm{N}^{+}$nitrogen form also increased slightly from 3 to $5 \mathrm{ppm}$.

Table 3. The approximate nitrogen concentration in the octahedral growth sectors at the periphery of the plates before and after RHPHT annealing

\begin{tabular}{|c|c|c|c|c|}
\hline \multirow{2}{*}{$\begin{array}{c}\text { Temperature, } \\
{ }^{\circ} \mathrm{C}\end{array}$} & \multicolumn{4}{|c|}{ Nitrogen concentration before $\rightarrow$ after RHPHT annealing, ppm $(+/-5 \%)$} \\
\cline { 2 - 5 } & $\mathrm{C}$-form & $\mathrm{N}^{+}$-form & A-form & $\mathbf{C + N}^{+}+\mathbf{A}$ \\
\hline 1900 & $121 \rightarrow 118$ & $8 \rightarrow 6$ & $35 \rightarrow 30$ & $164 \rightarrow 154$ \\
\hline 2100 & $115 \rightarrow 130$ & $9 \rightarrow 7$ & $36 \rightarrow 35$ & $160 \rightarrow 172$ \\
\hline
\end{tabular}




\begin{tabular}{|l|c|c|c|c|}
\hline 2300 & $173 \rightarrow 174$ & $2 \rightarrow 4$ & $9 \rightarrow 8$ & $184 \rightarrow 186$ \\
\hline 2500 & $167 \rightarrow 163$ & $3 \rightarrow 9$ & $4 \rightarrow 6$ & $174 \rightarrow 178$ \\
\hline 2700 & $169 \rightarrow 139$ & $3 \rightarrow 5$ & $8 \rightarrow 36$ & $180 \rightarrow 180$ \\
\hline
\end{tabular}

As can be seen from Table 3, the detectable nitrogen aggregation in IR absorption was observed at RHPHT annealing temperatures equal to $2500^{\circ} \mathrm{C}$ and above. The absorption spectra structure did not change practically after RHPHT annealing at lower temperatures. It should be noted that the IR absorption spectra did not contain any features of the second stage of nitrogen aggregation related to the generation of $\mathrm{B}$ defects.

\section{Cathodoluminescence}

The CL spectra of diamond plates before and after RHPHT annealing are shown in Figure 6. The spectra were recorded during the excitation of octahedral growth sectors. CL spectra structure before RHPHT annealing was typical for synthetic Ib-type diamonds grown from iron-nickel melt $[22,45,47,56-58]$. The spectra were dominated by the intense zerophonon line (ZPL) related to the nickel at $484 \mathrm{~nm}$ and a wide electron-phonon band with a maximum of about $540 \mathrm{~nm}$. The low-intensity Ni center was also observed - doublet at $884 \mathrm{~nm}$. Both centers had a simple atomic structure and contained one Ni atom according to [59-60].

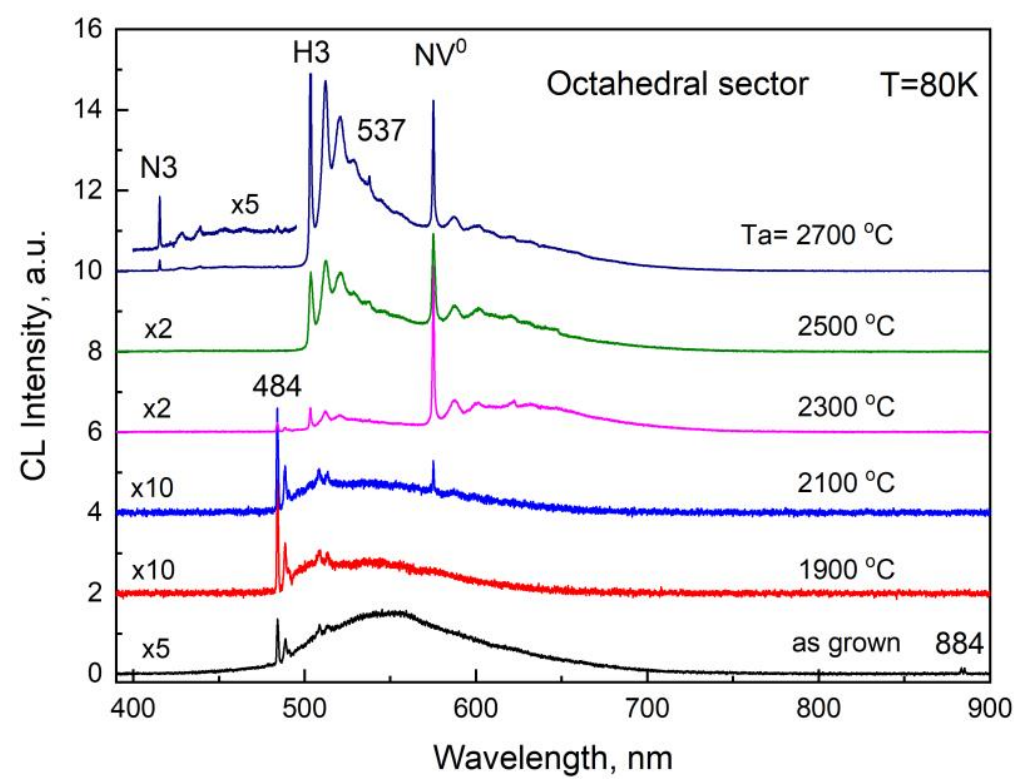

Figure 6 - CL spectra of diamond plates before and after RHPHT annealing recorded during the excitation of the octahedral growth sectors. The spectra are shifted along the ordinate for clarity.

The intensity of the $484 \mathrm{~nm}$ center almost did not change after RHPHT annealing at $1900^{\circ} \mathrm{C}-2100^{\circ} \mathrm{C}$. The center at $884 \mathrm{~nm}$ was not detected after an annealing temperature of 1900 ${ }^{\circ} \mathrm{C}$. ZPL at $575 \mathrm{~nm}$ appeared in the CL spectra related to the nitrogen-vacancy center in a neutral charging state $\left(\mathrm{NV}^{0}\right)$ [45] starting from $2100^{\circ} \mathrm{C}$. The formation of $\mathrm{NV}^{0}$-centers was observed after the plastic diamond deformation and high-temperature annealing under pressure $[48,61]$. The intensity of the $484 \mathrm{~nm}$ nickel center decreased significantly after annealing at $2300^{\circ} \mathrm{C}$. It was no longer dominant. The line at $503 \mathrm{~nm}$ appeared in the CL spectra along with the increase 
in the intensity of the $\mathrm{NV}^{0}$-center. The structure of the $503 \mathrm{~nm}$ center (H3-center) includes two nitrogen atoms and a vacancy [45]. The registration of the H3-center in the CL spectra indicates the formation of the simplest nitrogen aggregates in the form of two atoms at the nearest adjacent nodes of the diamond lattice. The further increase in the RHPHT annealing temperature to $2500^{\circ} \mathrm{C}$ caused the annealing of the $484 \mathrm{~nm}$ center, the increase in the intensity of the $\mathrm{NV}^{0}$ and $\mathrm{H} 3$-centers, and the appearance of the low intensity line at $537 \mathrm{~nm}$. The $537 \mathrm{~nm}$ center in the CL spectra appeared simultaneously with the H3-center [47]. There is an opinion [45] that the 537 $\mathrm{nm}$ center is a phonon repetition of $503 \mathrm{~nm}$ ZPL arising from the interaction of the electronic transition with $160 \mathrm{meV}$ phonon. The $415 \mathrm{~nm}$ line corresponding to the N3-center appeared in the $\mathrm{CL}$ spectra at $2700^{\circ} \mathrm{C}$. The structure of the $\mathrm{N} 3$-center includes 3 nitrogen atoms and a vacancy [45]. The formation of the N3-center after RHPHT annealing at $2700^{\circ} \mathrm{C}$ indicates the deeper aggregation of nitrogen corresponding to B-form.

Collins and Robertson [62] estimated the internal stresses ratio to the width of the $575 \mathrm{~nm}$ zero-phonon line measured at $77 \mathrm{~K}$ using the simple expression:

$$
\sigma=\mathrm{W}_{575} / 10 \text {. }
$$

where $\sigma$ is the stress value in GPa and $\mathrm{W}$ is FWHM line in meV. The application of this ratio to FWHM values of the $575 \mathrm{~nm}$ line extracted from Figure 6 showed that diamond plates contained significant internal stresses varying from about $0.27 \mathrm{GPa}$ to $0.71 \mathrm{GPa}$ after RHPHT annealing at temperatures above $2100^{\circ} \mathrm{C}$. This stress values obtained from ZPL width equal to $575 \mathrm{~nm}$ are comparable to that obtained from the spectral shift of $1332 \mathrm{~cm}^{-1}$ Raman line.

\section{Photoluminescence}

The PL spectra of diamond plates shown in Figure 7 were recorded at room temperature after RHPHT annealing and supplemented the results of the CL study. The PL spectra had the same structure and practically did not differ from those shown in Figure 7 for the RHPHT annealing temperature of $1900^{\circ} \mathrm{C}$ prior to annealing. The spectra contained a wide FL band with a maximum of about $530 \mathrm{~nm}$ along with the narrow $\mathrm{R}$ and $2 \mathrm{R}$ lines from the Raman spectra. The average PL intensity was approximately 10 calculations per second. The subsequent RHPHT annealing at higher temperatures caused the significant increase in PL intensity. $575 \mathrm{~nm}$ and 638 $\mathrm{nm}$ lines related to nitrogen vacancy centers appeared in the PL spectra starting from $2100^{\circ} \mathrm{C}$. The $638 \mathrm{~nm}$ line is related to the nitrogen-vacancy center in the negatively charged state [45] that was not excited during CL studies. As shown in Figure 7, $575 \mathrm{~nm}$ centers were formed predominantly in the central areas of the plates in the cubic growth sectors, and $638 \mathrm{~nm}$ centers were formed on the periphery of the plates in the octahedral sectors [44]. As in CL studies, the $503 \mathrm{~nm}$ line appeared in the PL spectra indicating the nitrogen aggregation after RHPHT annealing at $2300^{\circ} \mathrm{C}$. Its intensity, as well as the intensity of $575 \mathrm{~nm}$ and $638 \mathrm{~nm}$ lines, changed with the increase in RHPHT annealing temperature. It should be noted that RHPHT annealing of Almazot in the quasi-stationary mode at the pressure of $5.2 \mathrm{GPa}$ and temperature of $1870^{\circ} \mathrm{C}$ within 4 hours regularly carried out by the authors (see, for example, [10]) did not cause such intense luminescence. 

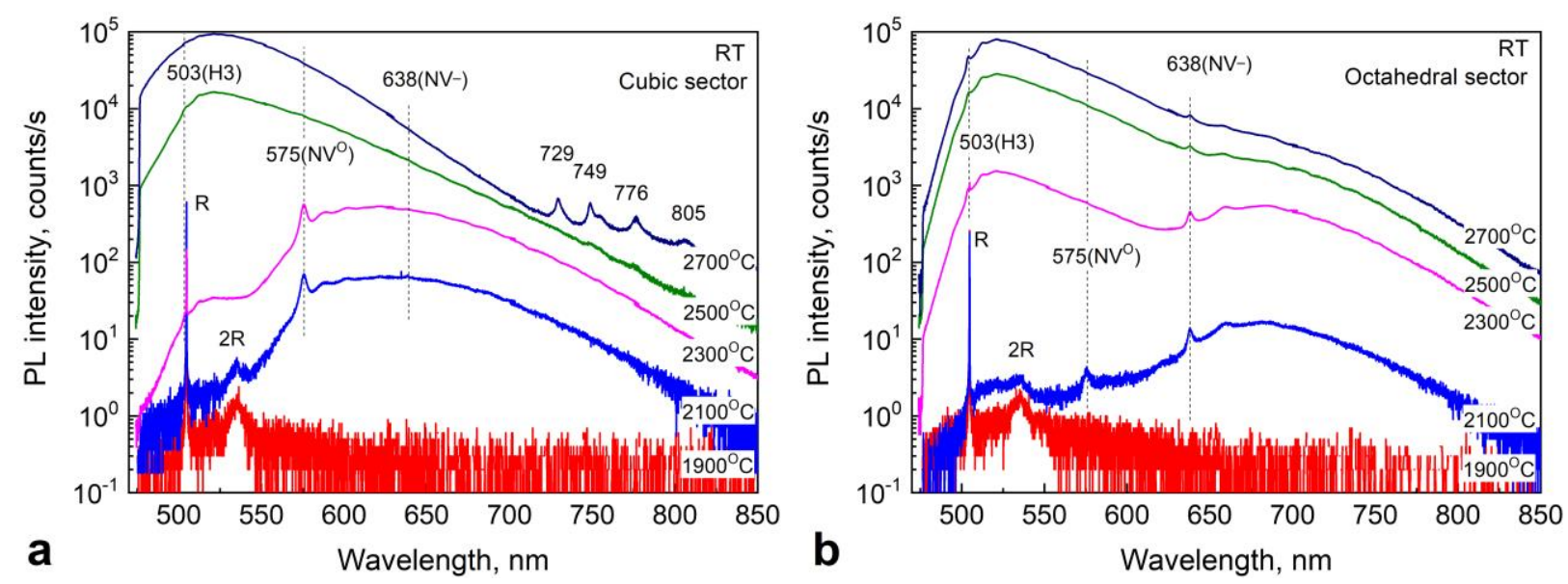

Figure 7 -PL spectra of diamond plates after RHPHT annealing: (a) - in the cubic growth sectors in the central areas of plates, (b) - in the octahedral growth sectors at the periphery of plates; the wavelength of the exciting irradiation is equal to $487 \mathrm{~nm}$

The lines at $729 \mathrm{~nm}, 749 \mathrm{~nm}, 776 \mathrm{~nm}$, and $805 \mathrm{~nm}$ from the central luminescent area of 4094-4 plate were present in the PL spectra even before annealing. These lines were observed in the PL spectra of synthetic HPHT diamonds grown from nickel-containing carbon solvents [45]. Therefore, their connection with nickel is most likely.

Our observations of changes in Almazot synthetic diamonds after RHPHT annealing correlate with the known information about the formation of nitrogen-vacancy centers in Ib-type diamonds during HPHT annealing. Almazot crystals contained the nitrogen admixture mainly in the $\mathrm{C}$-form after the synthesis. The nitrogen content was higher in octahedral growth sectors than in cubic one. The nitrogen share was in the form of the simplest aggregates - in the A-form in the central part of the crystals near the seed. The aggregated nitrogen fraction in the central part of the crystals depended on the temperature and synthesis duration.

It is known that the high-temperature annealing under pressure caused the plastic deformation of the diamond [63-64] to some extent. The authors of [64-65] observed noticeable manifestations of the plastic deformation at temperatures of $1000^{\circ} \mathrm{C}$ and higher. The diamond was plastically deformed due to partial graphitization [66] or due to stresses relaxation at the edges of growth sectors [32] even under the hydrostatic pressure distribution during the hightemperature annealing. The plastic deformation was accompanied by the formation of dislocations [48] and the generation of vacancies [67-68].

It is obvious that the rapid heating/cooling of the diamond plates in the high pressure container took place under conditions of a very inhomogeneous temperature and pressure distribution during RHPHT annealing. All this caused the inhomogeneous plastic deformation of the diamond plates. The consequences of the plastic deformation after RHPHT annealing were preserved in the form of stresses "imprinted" in the topogram of the diamond plates birefringence and manifested in the expansion of Raman, absorption, and luminescence lines. As follows from the Raman spectra, the stresses were both compressing and expanding the diamond crystal lattice. The latter prevailed.

The plastic deformation of diamonds during RHPHT annealing was a powerful "generator" of vacancies that participated in the "construction" of nitrogen-vacancy defects. The RHPHT annealed plates could be easily deformed with the increase in temperature, more vacancies were generated, and they were more mobile. The mobile vacancies were captured by 
nitrogen atoms and formed nitrogen-vacancy centers. The electron transfer from individual substituting nitrogen atoms to nitrogen-vacancy centers stimulated by the annealing switched some of these centers to the negatively charged state $[2,49,51]$.

The distribution of nitrogen vacancy centers in different growth sectors generally corresponded to the distribution of nitrogen impurities. More of them were generated in the octahedral growth sectors with a higher nitrogen concentration during RHPHT annealing. The vast majority of nitrogen-vacancy centers (clearly visible from the absorption spectra) captured electrons from the substituting nitrogen atoms and became negatively charged.

Another process accompanying RHPHT annealing was the diffusion of nitrogen atoms with the generation of its aggregates. The manifestation of the nitrogen aggregation was detected after RHPHT annealing at $2300^{\circ} \mathrm{C}$ as a result of $\mathrm{H} 2-$ and $\mathrm{H} 3$ defects formation. The concentration of these defects increased at higher RHPHT annealing temperatures, more complex aggregates containing three nitrogen atoms - N3 defects were formed. The sequence of nitrogen-vacancy defects formation with the increase in RHPHT annealing temperature (from simple to more complex) is the same as in quasi-stationary annealing. Qualitatively, RHPHT annealing led to the formation of identical nitrogen-vacancy defects, as well as quasi-stationary HPHT annealing. However, the number of these defects was significantly greater after RHPHT annealing. This difference was due to the higher concentration of vacancies formed under RHPHT annealing.

The difference between RHPHT and quasi-stationary HPHT annealing was that the aggregation was carried out along with the simultaneous generation of a large number of vacancies during RHPHT annealing. It is known that vacancies [6, 55, 69] or interstitial sites [70] created by the preliminary electron irradiation in diamonds accelerated the nitrogen aggregation. Therefore, the expectation of the accelerated nitrogen aggregation in diamonds is fully justified during RHPHT annealing. (The issue of the accelerated nitrogen aggregation in diamonds caused by the plastic deformation of their own defects was not considered in this study.)

The new effect of RHPHT annealing is to increase the luminescence efficiency in diamonds. It can be useful for some practical applications, for example, generation of scintillators [71] and fluorescent markers [9, 72-73].

\section{Conclusions}

We perform detailed study of the Ib type diamond plates after rapid annealing in the highpressure chamber. A part of the results related to the absorption and Raman/luminescence spectroscopy are reported in this communication. Based on these results we made a conclusion that diamond plates were plastic deformed during RHPHT annealing under the influence of nonuniform pressure and temperature distribution. The plastic deformation generated many vacancies, which, being mobile at RHPHT annealing temperatures, formed nitrogen-vacancy defects and accelerated nitrogen aggregation.

\section{Acknowledgments}

The authors are grateful to N.P. Vileishikova for the absorption measurement in the IR spectral range. N. Kazuchits is grateful to A.M. Zaitsev for the discussion of work results and attention to it. 


\section{Reference}

1. A.T. Collins, The colour of diamond and how it may be changed. J. Gemm, 27 №6 (2001) 341-359.

2. A.T. Collins, The detection of colour-enhanced and synthetic gem diamonds by optical spectroscopy. Diamond and related materials, 12 10-11 (2003) 1976-1983.

3. J.E. Shigley, C.M. Breeding, Optical defects in diamond: a quick reference chart, Gems \& Gemology 492 (2013) 108-111.

4. D.J. Cherniak, E.B. Watson, V. Meunier, N. Kharche, Diffusion of helium, hydrogen and deuterium in diamond: Experiment, theory and geochemical applications, Geochimica et Cosmochimica Acta 232 (2018) 206-224.

5. V.G. Vins, A.P.Yelisseyev, S.S. Lobanov, D.V. Afonin, A.Y. Maksimov, A.Y. Blinkov, APHT treatment of brown type Ia natural diamonds: Dislocation movement or vacancy cluster destruction, Diamond and related materials 19 7-9 (2010) 829-832.

6. A.P. Yelisseyev, V.G. Vins, S.S. Lobanov, D.V. Afonin, A.E. Blinkov, A.Y. Maximov, Aggregation of donor nitrogen in irradiated Ni-containing synthetic diamonds, Journal of crystal growth. 3181 (2011) 539-544.

7. N.M. Kazuchits, M.S. Rusetsky, V.N. Kazuchits and A.M. Zaitsev, Aggregation of nitrogen in synthetic diamonds annealed at high temperature without stabilizing pressure, Diamond and Related Materials 64 (2016) 202-207.

8. S. Eaton-Magaña, T. Ardon, A.M. Zaitsev, LPHT annealing of brown-to-yellow type Ia diamonds, Diamond and Related Materials 77 (2017) 159-170.

9. L. Dei Cas, S. Zeldin, N. Nunn, M. Torelli, A.I. Shames, A.M. Zaitsev, O. Shenderova, From fancy blue to red: Controlled production of a vibrant color spectrum of fluorescent diamond particles, Advanced Functional Materials 2919 (2019) 1808362.

10. N.M. Kazuchits, M.S. Rusetsky, V.N. Kazuchits, O.V. Korolik, V. Kumar, K.S. Moe, W. Wang, A.M. Zaitsev, Comparison of HPHT and LPHT annealing of Ib synthetic diamond, Diamond and Related Materials 91 (2019) 156-164.

11. A.M. Zaitsev, B. Deljanin, A. Peretti, M. Alessandri, W. Bieri, New generation of synthetic diamonds reaches the market (part C): Origin of yellow color in CVD-grown diamonds and treatment experiments, Contributions to Gemology 14 (2014) 41-55.

12. I.A. Dobrinets, V.G. Vins, A.M. Zaitsev, HPHT-treated Diamonds: Diamond Forever, Springer Science \& Business Media 181 (2013) 257.

13. J.E. Shigley, E. Fritsch, J.I. Koivula, N.V. Sobolev, I.Y. Malinovsky, Y.N. Pal'yanov, The gemological properties of Russian gem-quality synthetic yellow diamonds, Gems \& Gemology 294 (1993) 228-248.

14. R. Abbaschian, H. Zhu, C. Clarke, High pressure-high temperature growth of diamond crystals using split sphere apparatus, Diamond and related materials 14 11-12 (2005) 1916-1919.

15. A. Olejniczak, R. Tomala, B. Cichy, P. Głuchowski, M. Jakimow, A. Zieba, L. Kepinski, O. Ignatenko, W. Strek, Laser-driven proliferation of $\mathrm{sp}^{2}-\mathrm{sp}^{3}$ changes during anti-Stokes white light emission of m-diamonds, Carbon 146 (2019) 438-446.

16. A.V. Mudryi, T.P. Larionova, I.A. Shakin, G.A. Gusakov, G.A. Dubrov, V.V. Tikhonov, Optical properties of synthetic diamond single crystals, Semiconductors 385 (2004) 520523. 
17. N.M. Kazyuchits, A.V. Konovalova, I.I. Azarko, F.F. Yakotsuk, I.N. Bogdanov, Yu.K. Kabak, Effect of synthesis conditions on the impurity composition of STM "Almazot" diamond single crystals, Inorg. Mater. 502 (2014) 130-135.

18. G.B. Bokii, G.N. Bezrukov, Ju.A. Kluev, A.M. Naletov, V.I. Nepsha, Natural and Synthetic Diamonds, Nauka, Moscow, 1986 (in Russian).

19. I. Kiflawi, A.E. Mayer, P.M. Spear, J.A. Van Wyk, G.S. Woods, Infrared absorption by the single nitrogen and A defect centers in diamond, Philos. Mag. B 69 (1994) 11411147.

20. S.C. Lawson, D. Fisher, D.C. Hunt, M.E. Newton, On the existence of positively charged single-substitutional nitrogen in diamond, Journal of Physics: Condensed Matter 1027 (1998) 6171.

21. S.R. Boyd, I. Kiflawi, G.S. Woods, The relationship between infrared absorption and the A defect concentration in diamond, Philos. Mag. B 69 (1994) 1149-1153.

22. N.M. Kazuchits, M.S. Rusetsky, V.N. Kazuchits, A.M. Zaitsev, Cathodoluminescence of synthetic diamonds annealed at high temperature without stabilizing pressure, Diamond and Related Materials. 74 (2017) 41-44.

23. R.C. Burns, V. Cvetkovic, C.N. Dodge, D.J.F. Evans, M.L.T. Rooney, P.M. Spear, C.M. Welbourn, Growth-sector dependence of optical features in large synthetic diamonds, Journal of Crystal Growth 1042 (1990) 257-279.

24. H. Kanda, Nonuniform distributions of color and luminescence of diamond single crystals, New Diamond and Frontier Carbon Technology 172 (2007) 105-116.

25. H. Kanda, K. Watanabe, Distribution of nickel related luminescence centers in HPHT diamond, Diam. Relat. Mater 8 (1999) 1463-1469.

26. A. Yelisseyev, Y. Babich, V. Nadolinny, D. Fisher, B. Feigelson, Spectroscopic study of HPHT synthetic diamonds, as grown at $1500{ }^{\circ} \mathrm{C}$, Diam. Relat. Mater 11 (2002) 22-37.

27. A.P. Yelisseyev, J.W. Steeds, Y.V. Babich, B.N. Feigelson, A new approach to investigation of nickel defect transformation in the HPHT synthetic diamonds using local optical spectroscopy, Diam. Relat. Mater 15 (2006) 1886-1890.

28. I. Kiflawi, H. Kanda, S.C. Lawson, The effect of the growth rate on the concentration of nitrogen and transition metal impurities in HPHT synthetic diamonds, Diam. Relat. Mater 11 (2002) 204-211.

29. Y.V. Babich, B.N. Feigelson, Spatial distribution of the nitrogen defects in synthetic diamond monocrystals: data of IR mapping, Geochemistry International, 471 (2009) 9498.

30. E. Gaubas, T. Ceponis, A. Jasiunas, V. Kalendra, J. Pavlov, N. Kazuchits, E. Naumchik, M. Rusetsky, Lateral scan profiles of the recombination parameters correlated with distribution of grown-in impurities in HPHT diamond, Diamond and Related Materials. 47 (2014) 15-26.

31. C. Phaal, Plastic deformation of diamond, Philosophical Magazine 10107 (1964) 887891.

32. I.I. Vlasov, V.G. Ralchenko, E.D. Obraztsova, A.A. Smolin, V.I. Konov, Analysis of intrinsic stress distribution in grains of high quality CVD diamond film by micro-Raman spectroscopy, Thin Solid Films 308 (1997) 168-172.

33. I. Vlasov, V. Ralchenko, D. Zakharov, N. Zakharov, Intrinsic stress origin in high quality CVD diamond films, Physica status solidi (a) 1741 (1999) 11-18. 
34. M. Moore, M. Golshan, G. Kowalski, J. Reid, S. Collins, B. Murphy, Reciprocal-space mapping of synthetic and natural diamond, Journal of Physics D: Applied Physics, 32 (1999) A37.

35. J.B. Wu, M.L. Lin, X. Cong, H.N. Liu, P.H. Tan, Raman spectroscopy of graphene-based materials and its applications in related devices, Chemical Society Reviews 475 (2018) 1822-1873.

36. D. Kirillov, G.J. Reynolds, Linewidths of phonon lines of natural and synthetic diamonds, Applied physics letters 6513 (1994) 1641-1643.

37. N.V. Surovtsev, I.N. Kupriyanov, V.K. Malinovsky, V.A. Gusev, Y.N. Pal'yanov, Effect of nitrogen impurities on the Raman line width in diamonds, Journal of Physics: Condensed Matter 1124 (1999) 4767-4774.

38. T. Bauer, M. Schreck, H. Sternschulte, B. Stritzker, High growth rate homoepitaxial diamond deposition on off-axis substrates, Diamond and related materials 14 3-7 (2005) 266-271.

39. M. Muehle, M.K. Yaran, M.F. Becker, T. Schuelke, J. Asmussen, Y. Gu, D.K. Reinhard, T. A. Grotjohn. Quality and internal stress of single crystalline diamond synthesized by microwave plasma assisted chemical vapor deposition. In New Diamond and Nano Carbons Conference. 2012, May. Poster (available online at http://mipse.umich.edu/files/MIPSE_GS2012_Muehle2.pdf).

40. M.H. Grimsditch, E. Anastassakis, M. Cardona, Effect of uniaxial stress on the zonecenter optical phonon of diamond, Physical Review B 182 (1978) 901.

41. J.W. Ager III, M.D. Drory, Quantitative measurement of residual biaxial stress by Raman spectroscopy in diamond grown on a Ti alloy by chemical vapor deposition, Physical Review B 484 (1993) 2601.

42. S. Prawer, R.J. Nemanich, Raman spectroscopy of diamond and doped diamond, Philosophical Transactions of the Royal Society of London, Series A: Mathematical, Physical and Engineering Sciences 3621824 (2004) 2537-2565.

43. F. Ahmed, K. Durst, S. Rosiwal, J. Fandrey, J. Schaufler, M.Göken, In-situ tensile testing of crystalline diamond coatings using Raman spectroscopy, Surface and Coatings Technology 204 6-7 (2009) 1022-1025.

44. W.J.P. Van Enckevort, H.G.M. Lochs, Photoluminescence tomography as a method to image point-defect distributions in crystals: Nitrogen-vacancy pairs in synthetic diamonds, Journal of applied physics 641 (1988) 434-437.

45. A.M. Zaitsev, Optical Properties of Diamonds: a Data Handbook, Springer, Berlin, 2001.

46. Y. Nisida, Y. Mita, K. Mori, S. Okuda, S. Sato, S. Yazu, M. Okada, Color centers in annealing of neutron-irradiated type Ib and Ia diamonds, Materials Science Forum, 38-41 (1989) 561-566.

47. A.T. Collins, The characterization of point defects in diamond by luminescence spectroscopy. Diamond and related materials 1 5-6 (1992) 457-469.

48. E.J. Brookes, J.D. Comins, R.D. Daniel, R.M. Erasmus, A study of plastic deformation profiles of impressions in diamond, Diamond and related Materials 9 3-6 (2000) 11151119.

49. Y. Mita et al., Photochromism of $\mathrm{H} 2$ and $\mathrm{H} 3$ centres in synthetic type $\mathrm{Ib}$ diamonds, Journal of Physics: Condensed Matter 243 (1990) 8567. 
50. S.C. Lawson et al., The 'H2' optical transition in diamond: the effects of uniaxial stress perturbations, temperature and isotopic substitution, Journal of Physics: Condensed Matter 413 (1992) 3439.

51. V.G. Vins, A.P. Yelisseyev, V. Sarin, Physics behind the modern methods of enhancement of natural diamonds, Precious Metals and Gem Stones 12180 (2008) 155163; ibid. 2182 (2009) 132-145; ibid., 3183 (2009) 127-148. (in Russian).

52. Y.V. Babich, B.N. Feigelson, I.Y. Babich, A.I. Chepurov, Specifics of the distribution of nitrogen defects in synthetic diamonds of cubic habit: IR mapping data, Geochemistry International 4810 (2010) 1028-1034.

53. S.C. Lawson, H. Kanda An annealing study of nickel point defects in high-pressure synthetic diamond, Journal of applied physics 738 (1993) 3967-3973.

54. S.C. Lawson, H. Kanda, Nickel in diamond: an annealing study, Diamond and Related Materials 2 2-4 (1993) 130-135.

55. J.R. Kim, D.K. Kim, H. Zhu, R. Abbaschian, High pressure and high temperature annealing on nitrogen aggregation in lab-grown diamonds. Journal of materials science 4619 (2011) 6264-6272.

56. T.A. Collins, P.M. Spear, The $1.40 \mathrm{eV}$ and $2.56 \mathrm{eV}$ centres in synthetic diamond, J. Phys. C: Solid State Phys 16 (1983) 963-973.

57. A.T. Collins, M. Stanley, Absorption and luminescence studies of synthetic diamond in which the nitrogen has been aggregated, J. Phys. D. Appl. Phys 18 (1985) 2537-2545.

58. A.T. Collins, Spectroscopic studies of synthetic diamonds grown by the temperature gradient method, Science and Technology of New Diamond, KTK Scientific Publishers, Tokyo Terra Scientific Publishing Company Tokyo (1990) 273-278.

59. E. Pereira, L. Santos, L. Pereira, D.M. Hofmann, P. Christmann, W. Stadler, B.K. Meyer, Slow emission of the $2.56 \mathrm{eV}$ centre in synthetic diamond, DRM 4 (1994) 53-58.

60. M.N. Nazare, P.W. Mason, G.D. Watkins, H. Kanda, Optical detection of magnetic resonance of nitrogen and nickel in high-pressure synthetic diamond, Phys. Rev. B 51 (1995) 16741.

61. H. Kanda, X. Jia, Change of luminescence character of Ib diamonds with HPHT treatment, Diamond and related materials 10 9-10 (2001) 1665-1669.

62. A.T. Collins, S.H. Robertson, Cathodoluminescence studies of sintered diamond, Journal of materials science letters 46 (1985) 681-684.

63. R.C. DeVries, Plastic deformation and "work-hardening” of diamond, Materials Research Bulletin 1011 (1975) 1193-1199.

64. D.J. Weidner, Y. Wang, M. T. Vaughan, Strength of diamond, Science, 2665184 (1994) 419-422.

65. C.A. Brookes, V.R. Howes, A.R. Parry, Multiple slip in diamond due to a nominal contact pressure of $10 \mathrm{GPa}$ at $1000^{\circ} \mathrm{C}$, Nature 3326160 (1988) 139-141.

66. M. Seal, Graphitization and plastic deformation of diamond, Nature 1824645 (1958) 1264-1267.

67. T. Evans, S.T. Davey, S.H. Robertson, Photoluminescence studies of sintered diamond compacts, Journal of materials science, 197 (1984) 2405-2414.

68. E. Gaillou, J.E. Post, N.D. Bassim, A.M. Zaitsev, T. Rose, M.D. Fries, J.E. Butler, Spectroscopic and microscopic characterizations of color lamellae in natural pink diamonds. Diamond and Related Materials 1910 (2010) 1207-1220. 
69. A.T. Collins, Vacancy enhanced aggregation of nitrogen in diamond, Journal of Physics C: Solid State Physics 1314 (1980) 2641.

70. R. Jones, J.P. Goss, H. Pinto, D.W. Palmer, Diffusion of nitrogen in diamond and the formation of A-centres. Diamond and Related Materials 53 (2015) 35-39.

71. O.G. Lysenko, V.I. Grushko, E.I. Mitskevich, G.D. Ilnitska, A.Yu. Boyarintsev, Yu.D. Onufriev, V.F. Popov, L.G. Levchuk, N.M. Kazuchits, M.S. Rusetsky, V.V. Lysakovskyi, S.A. Ivakhnenko, Luminescent and radiation characteristics of monocrystalline diamond powders, Journal of Superhard Materials 411 (2019) 17-23.

72. O.A. Shenderova, A.I. Shames, N.A. Nunn, M.D. Torelli, I. Vlasov, A. Zaitsev, Synthesis, properties, and applications of fluorescent diamond particles, Journal of Vacuum Science \& Technology B, Nanotechnology and Microelectronics: Materials, Processing, Measurement, and Phenomena 373 (2019) 030802.

73. N. Nunn, N. Prabhakar, P. Reineck, V. Magidson, E. Kamiya, W.F. Heinz, O. Shenderova, Brilliant blue, green, yellow, and red fluorescent diamond particles: synthesis, characterization, and multiplex imaging demonstrations, Nanoscale 1124 (2019) 11584-11595. 